\title{
Disaster Preparedness for Natural Hazards Current Status in India
}
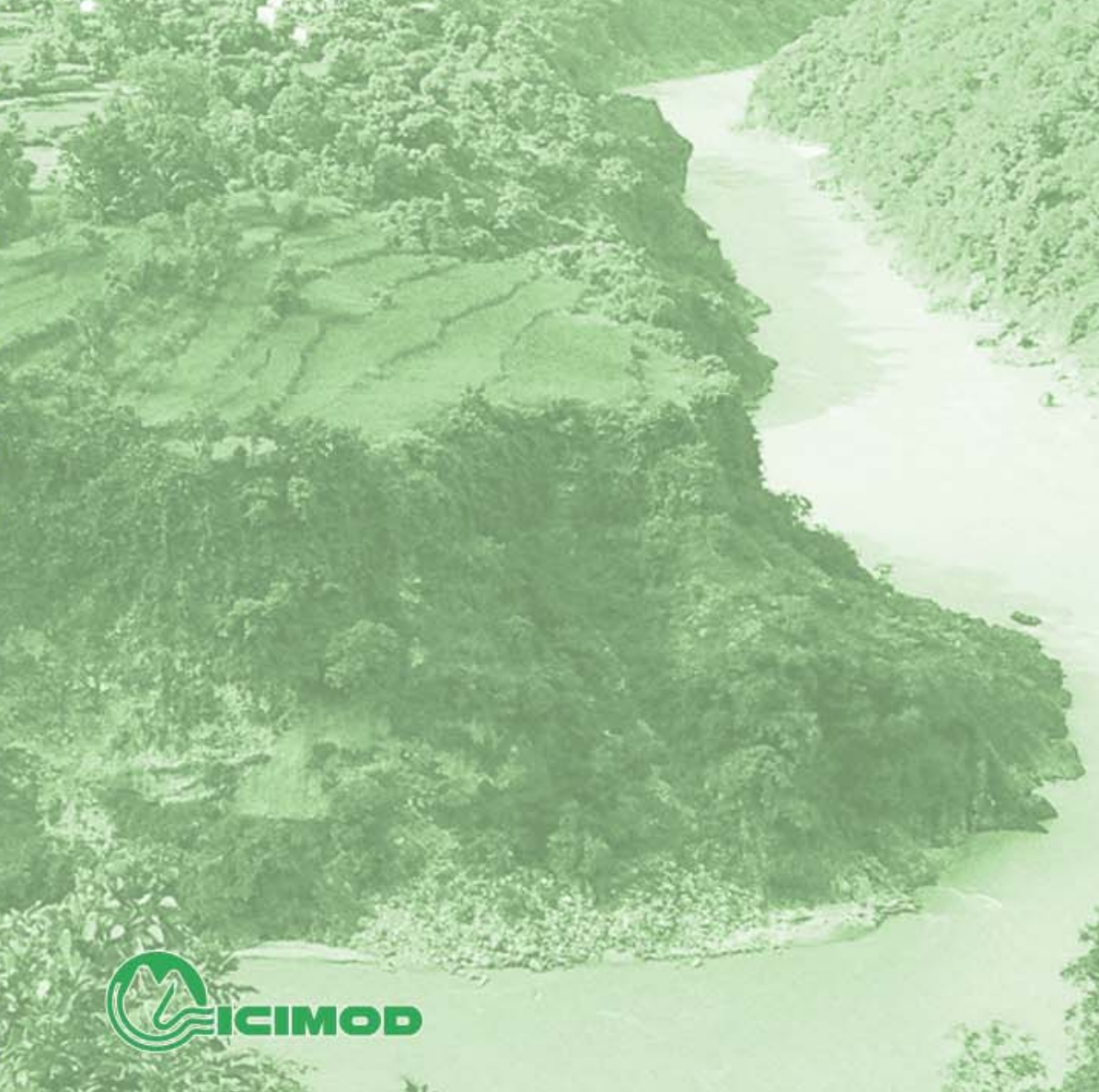

is:
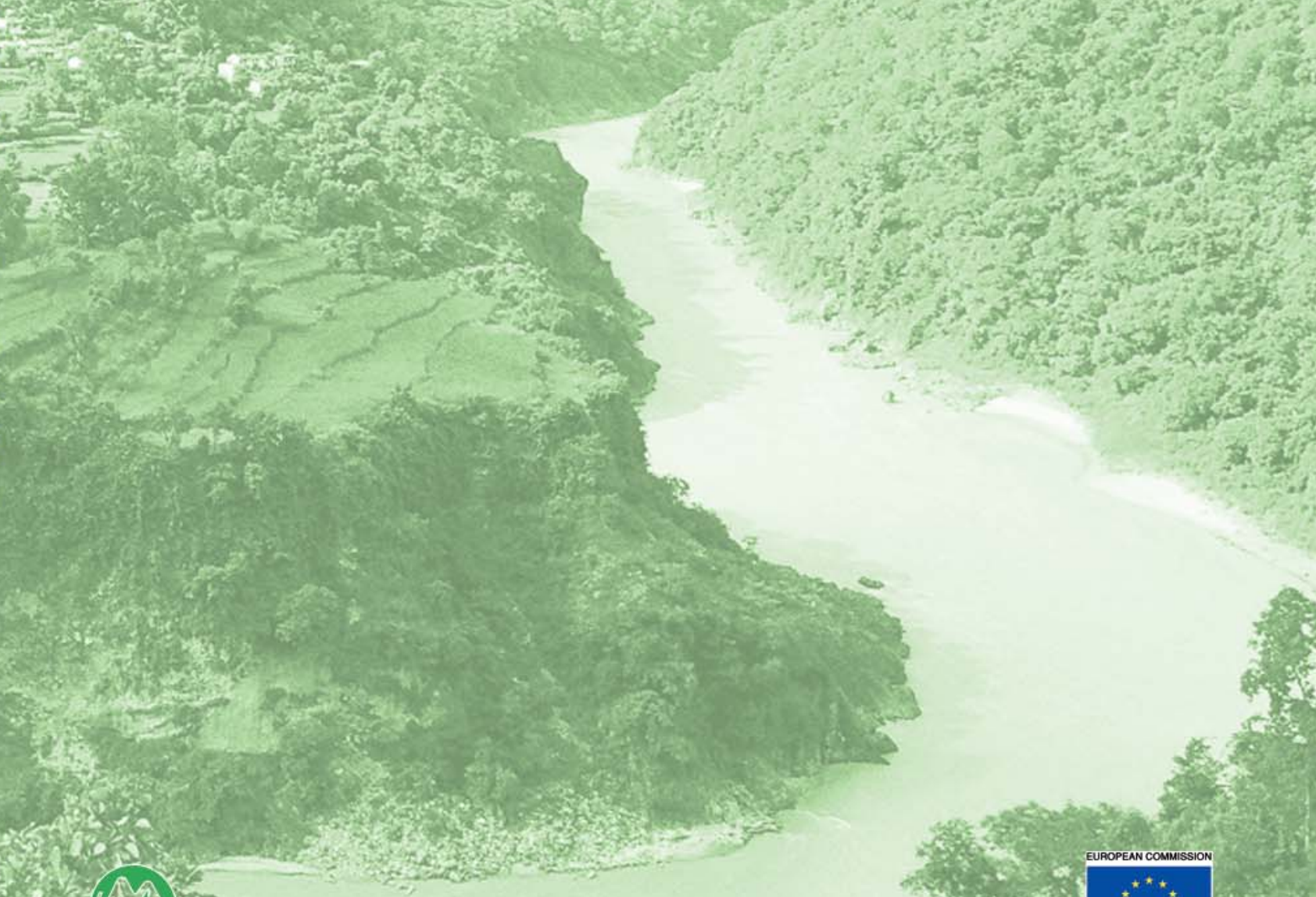


\section{About the Organisations}

\section{International Centre for Integrated Mountain Development}

The International Centre for Integrated Mountain Development (ICIMOD) is an independent 'Mountain Learning and Knowledge Centre' serving the eight countries of the Hindu Kush-

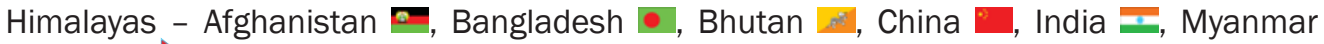
- Nepal $\mathbf{5}$, and Pakistan $\mathbb{C}$ - and the global mountain community. Founded in 1983, ICIMOD is based in Kathmandu, Nepal, and brings together a partnership of regional member countries, partner institutions, and donors with a commitment for development action to secure a better future for the people and environment of the extended Himalayan region. ICIMOD's activities are supported by its core programme donors: the governments of Austria, Denmark, Germany, Netherlands, Norway, Switzerland, and its regional member countries, along with over thirty project co-financing donors. The primary objective of the Centre is to promote the development of an economically and environmentally sound mountain ecosystem and to improve the living standards of mountain populations.

\section{European Commission Humanitarian Aid (ECHO)}

EUROPEAN COMMISSION

The European Union as a whole (i.e., the Member States and the

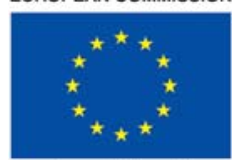
Commission) is one of the world's largest humanitarian aid donors; the Humanitarian Aid department (ECHO) is the service of the European Commission responsible for this activity. ECHO funds relief operations for victims of natural disasters and conflicts outside the European Union.

Humanitarian Aid Aid is channelled impartially, straight to victims, regardless of their race, religion, and political beliefs.

DIPECHO stands for disaster preparedness in ECHO. It supports projects aimed at increasing the resilience of communities at risk of natural disasters by funding training, capacity building, awareness raising, early warning systems, and advocacy activities in the field of disaster risk reduction. 


\section{Disaster Preparedness}

for Natural Hazards:

Current Status in India 


\section{Disaster Preparedness for Natural Hazards: Current Status in India}

A consultancy report by Chandrani Bandyopadhyay

International Centre for Integrated Mountain Development (ICIMOD)

Kathmandu, Nepal

June 2007 


\section{Copyright (C) 2007}

International Centre for Integrated Mountain Development (ICIMOD)

All rights reserved

\section{Published by}

International Centre for Integrated Mountain Development

G.P.O. Box 3226

Kathmandu, Nepal

\section{ISBN 9789291150380}

Front cover: Village between Devprayag and Ukhimath on the river Alaknanda, Uttarakhand, India - Prashant Sharma

\section{Editorial team}

Mats G. Eriksson (Series Coordinator)

Greta M. Rana (Consultant Editor)

A. Beatrice Murray (Senior Editor)

Dharma R. Maharjan (Layout Design)

\section{Printed and bound in Nepal by}

Hill Side Press $(P)$ Ltd.

Kathmandu

\section{Reproduction}

This publication may be reproduced in whole or in part and in any form for educational or non-profit purposes without special permission from the copyright holder, provided acknowledgement of the source is made. ICIMOD would appreciate receiving a copy of any publication that uses this publication as a source.

No use of this publication may be made for resale or for any other commercial purpose whatsoever without prior permission in writing from ICIMOD.

\section{Note}

The views and interpretations in this publication are those of the author. They are not attributable to ICIMOD and do not imply the expression of any opinion concerning the legal status of any country, territory, city or area of its authorities, or concerning the delimitation of its frontiers or boundaries, or the endorsement of any product.

This report was edited into the current form without further review by the author. 


\section{Contents}

Foreword $\quad$ V

Preface vii

Conclusions from the Regional Workshop on Disaster Preparedness Plans ix

Acknowledgements

Executive Summary

Acronyms and Abbreviations xiv

Some Key Terms $\quad$ xV

Chapter 1: Introduction 1

Chapter 2: Natural Hazards in India $\quad 5$

Chapter 3: National Disaster Preparedness 13

Chapter 4: National-level Disaster Management Planning 29

Chapter 5: State and Local-level Disaster Management Planning 39

Chapter 6: $\quad$ Disaster Preparedness Plans - Strengths and Weaknesses $\quad 49$

Chapter 7: Communicating and Sharing Knowledge About Disaster

Preparedness $\quad 51$

Chapter 8: Conclusions and Recommendations $\quad 57$

$\begin{array}{ll}\text { Bibliography } & 61\end{array}$

Annexes (on CD-ROM in back pocket)

Annex 1: Terms of Reference

Annex 2: National Disaster Response Plan

Annex 3: Maharashtra State Disaster Management Action Plan

Annex 4: Model Template for Preparation of District Disaster Management Plan

Annex 5: District Disaster Management Plan, Maharajganj District, Uttar Pradesh 
T

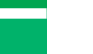




\section{Foreword}

Inhabitants in the Himalayan region are exposed to many natural hazards. The mountain ranges are young with an unstable geology, steep slopes, and a climate that is difficult to predict. As a result, the region is highly susceptible to natural hazards such as floods and flash floods, landslides, and earthquakes. In populated areas, these can lead to disaster. Vulnerable groups - the poor, women, and children - are often hit hardest.

Since its establishment in 1983, ICIMOD has dedicated much of its work to examining ways to reduce the risk of disasters from natural hazards, thereby working towards the decreased physical vulnerability of people in the Hindu Kush-Himalayas. This work has encompassed training courses, hazard mapping, landslide mitigation and control, mountain risk engineering, watershed management, vulnerability assessment, and much more. ICIMOD has also fostered regional and transboundary dialogue for improved management of both the resources provided and the risks threatened by the big rivers in the Himalayan region; sharing of hydro-meteorological data and information among the countries in the region is of particular importance for mitigating the risk of riverine and flash floods in the major river basins.

This publication is one of a series produced under the project 'Living with risk - sharing knowledge on disaster preparedness in the Himalayan region', implemented by ICIMOD during a 15-month period in 2006 and 2007. The project was funded by the European Commission through their Humanitarian Aid department (DG ECHO) as part of the Disaster Preparedness ECHO programme (DIPECHO) in South Asia, and by ICIMOD. Through this project, ICIMOD has endeavoured to encourage knowledge sharing and to strengthen capacity among key practitioners in the field of disaster preparedness and management. This has been done through training courses, workshops, knowledge compilation and dissemination, and the establishment of a website (www. disasterpreparedness.icimod.org).

The publications resulting from this project include baseline assessments of the disaster preparedness status in the four target countries (Bangladesh, India, Nepal, and Pakistan); case studies and a framework on local knowledge for disaster preparedness; and gender and vulnerability aspects in disaster risk reduction. The publications, training sessions, and workshops were undertaken in the context of the 'Hyogo Framework for Action 2005-2015' which recommends that regional organisations should promote sharing of information; undertake and publish baseline assessments of disaster risk reduction status; and undertake research, training, education, and capacity building in the field of disaster risk reduction. 
The long-term mission to bring the Himalayan region to an acceptable level of disaster risk has only just begun. The countries in the region are among the most disaster prone in the world in terms of number and severity of disasters, casualties, and impact on national economies. Only by strong commitment, hard work, and joint efforts can this situation be improved. It is ICIMOD's hope that our collective endeavours will help improve disaster risk reduction in the mountain region we are committed to serve.

\author{
Dr. Andreas Schild \\ Director General \\ ICIMOD
}




\section{Preface}

This report is one of four status reports on disaster preparedness planning covering four countries; viz., Bangladesh, India, Nepal, and Pakistan. The purpose of these reports is to provide an opportunity for the reader to get a quick overview of the current status on disaster preparedness documents in place and the institutions governing the implementation of these documents in the respective countries.

The reports are based on consultancies undertaken as part of the project 'Living with risk - sharing knowledge on disaster preparedness in the Himalayan region', implemented by ICIMOD, and funded by the European Commission through its Humanitarian Aid Department (DG ECHO) as part of the Disaster Preparedness ECHO Programme (DIPECHO) in South Asia, and by ICIMOD. The project takes off from the Hyogo Framework for Action 2005-2015 (HFA) which provides guidance on the roles regional organisations, such as ICIMOD, can play in long-term work towards reducing the risks of disaster. One recommendation by HFA is to undertake and publish baseline assessments of the status of disaster risk reduction.

As part of this project, a 'regional workshop on disaster preparedness plans' was held in Kathmandu in August 2006. The main objective of this workshop was to discuss the status of disaster preparedness as reflected in policies, strategies, plans, and other relevant documents available, or being developed, in the four countries. Particular interest was given to identifying gaps and shortcomings in the functioning and implementation of these guiding documents. First drafts of these country status reports were prepared for the workshop and formed the basis for the discussion and gap analysis. The reports have since been updated, improved, and extended. The outcome of the workshop was summarised in 15 concluding points, highlighting the status of disaster preparedness (DP), in particular, and disaster management (DM), in general, in the region. These 15 concluding points follow below.

The complete compilation of all documents at all governance levels, covering all types of disaster and providing full descriptions of all implementing institutions is an immense task, and it is beyond the scope of this project. ICIMOD has a mandate to focus primarily on mountain hazards, and therefore the scope of the consultancy has been to cover earthquakes, landslides, and floods, including flash floods (see Annex 1 for Terms of Reference). Furthermore, the study focused on documents and institutions governing disaster preparedness planning at the central, national level, with more limited coverage given to district and community levels. Hence, the reports are not 
exhaustive in terms of covering all natural hazards. Nevertheless, the documents and institutions governing disaster preparedness at the national level do, in many cases, take a multi-hazard approach. In conclusion, the present document will give the reader a good, albeit quick, overview of the status of disaster preparedness planning for natural hazards. As such, it is the hope of ICIMOD that it will prove helpful as a source of information and thereby support the joint efforts undertaken by many government and non-government organisations towards a Himalayan region that is better prepared to mitigate the impacts of disasters.

Dr. Mats G. Eriksson

Water, Hazards and

Environmental Management ICIMOD 


\section{Conclusions from the Regional Workshop on Disaster \\ Preparedness Plans for Natural Hazards \\ (Kathmandu, 7-9 August 2006)}

\section{General Observations}

1. Disaster preparedness (DP) has to be approached holistically because it is difficult to isolate preparedness from other components of disaster management (DM) such as reduction, response, and recovery.

2. A paradigm shift in DM from a relief-driven approach to a more preparednessdriven approach is occurring.

3. Local communities should be at the centre of DM plans. They are the first victims of natural hazards and the first respondents.

\section{Development and Vulnerable Groups}

4. DM should be integrated into national development plans for improved sustainable livelihoods and poverty reduction.

5. A multi-hazard approach is crucial as most communities are exposed to hazards that have interacting and cascading effects.

6. Vulnerable groups and marginalised people are insufficiently addressed in DM plans.

\section{Institutions and Policies}

7. The political will to direct sufficient resources is essential for the efficient implementation of existing DM plans.

8. Planning for DM is an iterative process that should be based on the efficient use of already existing resources.

9. Roles and responsibilities for DM of all stakeholders at the national, regional, and local levels need to be clarified. DM should be a priority on the national political agenda.

\section{Knowledge and capacities}

10. Local knowledge should be respected and combined with other knowledge to improve the design and implementation of DM activities.

11. Learning from past disaster events through research and documentation is important in order to anticipate and respond to future disasters more effectively than is currently the case.

12. Education and training in DM is necessary for awareness and capacity building of all stakeholders.

\section{Communication and Cooperation}

13. Insufficient coordination prevails among key actor in the field of DM.

14. Functional and efficient communication among key actors at local, national, and international levels needs to be improved.

15. Data and information sharing at a regional transboundary level needs to be strengthened and requires appropriate capacity and technology. 


\section{Acknowledgements}

This report has been written at a time when the entire nation is moving on a fast track towards a resilient India. The author thanks all those people who have made this possible through their vision, commitment, and dedication.

The author thanks ICIMOD, especially Dr Mats Eriksson, for providing the opportunity to be a part of this initiative and also for encouragement and constructive comments on the report. Special thanks are also due to Mr. P.G. Dhar Chakrabarti, Executive Director, National Institute of Disaster Management and Director, SAARC Disaster Management Centre, for his constant support and succinct comments for improvement.

Last, but not the least, many thanks to my family, especially Bhasker and Kuhu, for being there, no matter what! 


\section{Executive Summary}

The introduction to India, its historical experience of natural disasters, and ancient records that contain measures to address them or be prepared for them familiarise us with the environment of disaster preparedness in India and the efforts made to improve them and institutionalise them that make up the rest of the text.

This is followed by a section placing India globally in terms of vulnerability to recurrent and concomitant disasters, particularly floods, landslides, and earthquakes. Reasons for this lie in its situation in South Asia, openness to the sea along a lengthy coastline, the vastness and diversity of its subcontinental terrain, its many mighty rivers, and the rugged geomorphology of the Himalayas. Human-induced reasons are also taken into account, not least the changing demography of a growing population and the reactions to recurrent disasters that lead to activities on yet more vulnerable or degraded land, which in turn leave people and assets vulnerable to yet more disasters.

The report continues by describing the disaster management structure that was built up following Indian Independence in 1947, and which is the basic structure upon which changes and revisions are taking place currently. A comprehensive description is given of the federal structure and the avenues through which power is devolved to the states, with the central government in a supportive, enabling role by providing financial and physical resources, warning, transport, inter-state movement, and emergency food supplies.

Nationally the Home Ministry carries out this work through a Central Relief Commissioner who receives information through the Meteorological Department's early warning and forecasting systems and the Central Water Commission. There is also a Crisis Management Group to coordinate the activities of central ministries and review the contingency plans of the state governments. Overarching this are three committees at cabinet level: The National Crisis Management Committee (NCMC) headed by the Cabinet Secretary and two other Cabinet Committees, one on Natural Calamities and the other on Security.

At state level, the Relief Commissioners look after relief and rehabilitation for disasters and are under the Chief Secretary, and at the district level natural disasters are the responsibility of the District Collectors or Magistrates. Funds, namely, Calamity Relief Funds, are allocated, and these come in varying proportions from the national and state levels.

This structure has been institutionalised since 1947, and it is on the base established by this structure that the new paradigm perspective is taking place and institutional changes introduced. 
Following the International Decade for Natural Disaster Reduction (IDNDR), the concern shifted from relief to prevention, especially considering the loss of development gains that each ensuing disaster brings. The text describes in good detail the initiatives from 1994 in the form of the establishment of a Central Sector Scheme on Disaster Management and the series of Finance Commissions and National Plans that have emphasised the integration of preparedness and disaster management at all levels of planning in India. Instrumental, however, in tabling the idea of a disaster management plan at overall national level as a promoting template was the High Powered Committee (HPC) on Disaster Management. It prepared a report in 2001 that contained wideranging recommendations for a system of disaster management throughout the country at various levels, backed by a National Disaster Response Plan (NDRP). The acceptance of this report by the Government of India put the wheels in motion to integrate disaster preparedness planning into the plans and activities of all states and districts through to villages in India. The HPC also formulated a model district disaster management plan that set down stipulations for background analysis and procedures.

On the ground, since 2002, the shift in paradigm is being institutionalised through a National Disaster Management Framework and later, in 2005, added impetus was given to this with a legal framework; viz., The National Disaster Management Act. Following the act it became mandatory to establish a National Disaster Management Authority (NDMA) under the chairmanship of the Prime Minister with a National Executive Committee to assist it. Through its auspices a National Plan for Disaster Management was to be prepared to lay down national policy. A National Institute of Disaster Management (NIDM) was then established to train; and also to carry out research and support policy formulation as well as give support to other institutions in the field throughout the country.

The Act promotes the establishment of disaster management authorities through to the state and district levels and down to the village committees. The structure at state and district levels follows the national-level structure. In terms of fund allocation and authority and responsibility for preparedness planning and mitigation measures, the procedures are quite comprehensive.

Supporting initiatives have been the government's introduction of an Incident Command System, for which training was undertaken in the USA by selected personnel, and emergency support functions. Plans, checklists, and standard operating procedures (SOPs) have all been prepared by the National Disaster Management Authority.

The paper describes the formulation of plans at different levels of governance. A district plan template was prepared by the NIDM in 2005 and planning is being promoted right through to the community level.

It is clear from the narrative that efforts are on to merge all the components of disaster preparedness and risk reduction into a comprehensive whole. Arrangements include not only the huge administrative machinery of the Government of India, but also the private sector and non-government actors. This all depicts a very busy and active 
burst of planning as India moves towards the paradigm of preparedness and poises to institutionalise this paradigm, fixing it, as it were, in the national psyche.

Such ambitious plans and activities suffer also from weaknesses, and these generally fall between the process and the actual practice. For instance, although the government accepted the National Disaster Response Plan and certain concepts have been implemented, the entire plan has not. The Act of 2005 provides for a national plan for managing disasters, but there are no clear guidelines. At other levels, although state to district and community planning for disaster management has been introduced conceptually and responsible parties identified, different states are at different stages in the exercise. Until recently there was no real institutional back-up. The Act of 2005 rectifies that to a certain extent. Previously the coordination and control structure in disaster preparedness was poorly defined and, unless an officer had a great deal of personal commitment, preparedness planning suffered. Capacity-building is of course the key, and 10 states have already trained district-level officers.

As far as communicating and sharing knowledge is concerned, a National Communication Plan has been drawn up that envisages a dedicated communication system using the latest technologies. Communications have been strengthened by using the police network (POLNET) and a nation-wide electronic inventory, the India Disaster Resource Network (IDRN), which has information about equipment, human resources, and critical supplies from district level onwards. Additionally GIS is being used to provide maps that will be useful for identifying hazards and an on-line India Disaster Knowledge Network (IDKN) is being established.

Regionally, a SAARC Disaster Management Centre (SDMC) was established in New Delhi in 2006, and there is also a Bay of Bengal Initiative for Multi-Sectoral Technical and Economic Cooperation (BIMSTEC) that is considering making disaster management one of its key areas of cooperation.

Recommendations focus on concerted promotion of disaster preparedness nationwide; a closer look at urban areas and their needs; thorough integration of plan implementation, both vertically and horizontally; building on the NDRP rather than framing a completely new national plan; holding regular drills; completing plans within a specified time frame; and that states ensure that their District Disaster Management Authorities are now fully notified and established.

In conclusion, the status appears to be that India has accepted that pre-disaster planning and preparedness is essential, and a hive of activity ensued after IDNDR. Many initiatives took place concomitantly, and because of this it is often difficult to determine what initiative is driving what. However, it is clear that each of these initiatives has given impetus to others and the clock will not be turned back in relation to preparedness planning. Although the driving force is the government, the government has made efforts to include all sectors into what is a comprehensive vision of a nation that is as prepared to the greatest possible extent for whatever natural disaster comes next. 


\section{Acronyms and Abbreviations}

$\begin{array}{ll}\text { BIMSTEC } & \text { Bay of Bengal Initiative for Multi-Sectoral Technical and Economic } \\ & \text { Cooperation } \\ \text { BMTPC } & \text { Building Materials and Technology Promotion Council } \\ \text { CMG } & \text { Crisis Management Group } \\ \text { CRF } & \text { Calamity Relief Fund } \\ \text { DDM } & \text { Department of Disaster Management } \\ \text { DDMP } & \text { District Disaster Management Plan } \\ \text { DDMA } & \text { District Disaster Management Authority } \\ \text { DMAP } & \text { Disaster Management Action Plan } \\ \text { EM-DAT } & \text { emergency disasters' database } \\ \text { EOC } & \text { Emergency Operations' Centre } \\ \text { ESF } & \text { emergency support functions } \\ \text { GDP } & \text { gross domestic product } \\ \text { GIS } & \text { geographic information system } \\ \text { HPC } & \text { High-powered Committee on Disaster Management } \\ \text { ICS } & \text { Incident Command System } \\ \text { IDNDR } & \text { International Decade for Natural Disaster Reduction } \\ \text { IDKN } & \text { India Disaster Knowledge Network } \\ \text { IDRN } & \text { India Disaster Resource Network } \\ \text { IFRC } & \text { International Federation of the Red Cross and Red Crescent } \\ \text { IMD } & \text { Indian Meteorological Department } \\ \text { NCDM } & \text { National Centre for Disaster Management } \\ \text { NCMC } & \text { National Crisis Management Committee } \\ \text { NDMA } & \text { National Disaster Management Authority } \\ \text { NDMF } & \text { National Disaster Management Framework } \\ \text { NDRF } & \text { National Disaster Response Force } \\ \text { NDRP } & \text { National Disaster Response Plan } \\ \text { NEC } & \text { National Executive Committee } \\ \text { NGO } & \text { non-government organisation } \\ \text { NIDM } & \text { National Institute for Disaster Management } \\ \text { NPDM } & \text { National Policy on Disaster Management } \\ \text { OFDA/CRED } & \text { Office of the US Foreign Disaster Assistance/ Centre for Research on } \\ \text { POLNET } & \text { the Epidemiology of Disasters } \\ \text { police network } \\ \text { SAARC } & \text { South Asian Association for Regional Cooperation } \\ \text { SDMA } & \text { State Disaster Management Authority } \\ \text { SDMC } & \text { SAARC Disaster Management Centre } \\ \text { SOP } & \text { standard operating procedure } \\ \text { UNDP } & \text { United Nations Development Programme } \\ \text { UT } & \text { Union Territory } \\ & \end{array}$




\section{Some Key Terms}

Capacity - A combination of all the strengths and resources available within a community, society, or organisation that can reduce the level of risk, or the effects of a disaster.

Disaster - A serious disruption of the functioning of a community or a society causing widespread human, material, economic, or environmental losses which exceed the ability of the affected community or society to cope using its own resources.

Disaster risk reduction (disaster reduction) - The conceptual framework of elements considered with the possibilities to minimise vulnerabilities and disaster risks throughout a society, to avoid (prevention) or to limit (mitigation and preparedness) the adverse impacts of hazards, within the broad context of sustainable development.

Hazard - A potentially damaging physical event, phenomenon or human activity that may cause the loss of life or injury, property damage, social and economic disruption or environmental degradation.

Mitigation - Structural and non-structural measures undertaken to limit the adverse impact of natural hazards, environmental degradation and technological hazards.

Preparedness - Activities and measures taken in advance to ensure effective response to the impact of hazards, including the issuance of timely and effective early warnings and the temporary evacuation of people and property from threatened locations.

Resilience/resilient - The capacity of a system, community or society potentially exposed to hazards to adapt, by resisting or changing in order to reach and maintain an acceptable level of functioning and structure. It is determined by the degree to which the social system is capable of organising itself to increase its capacity for learning from past disasters for better future protection and to improve risk reduction measures.

Risk - The probability of harmful consequences, or expected losses (deaths, injuries, property, livelihoods, economic activity disrupted or environmental damaged) resulting from interactions between natural or human-induced hazards and vulnerable conditions. Conventionally risk is expressed by the notation Risk $=$ Hazards $x$ Vulnerability. Some disciplines also include the concept of exposure to refer particularly to the physical aspects of vulnerability. A disaster is a function of the risk process. It results from the combination of hazards, conditions of vulnerability and insufficient capacity or measures to reduce the potential negative consequences of risk.

Risk assessment or analysis - A methodology to determine the nature and extent of risk by analysing potential hazards and evaluating existing conditions of vulnerability that could pose a potential threat or harm to people, property, livelihoods and the environment on which they depend.

Vulnerability - The conditions determined by physical, social, economic, and environmental factors or processes, which increase the susceptibility of a community to the impact of hazards. 